\title{
JACCOUD'S ARTHROPATHY ASSOCIATED WITH PSORIATIC ARTHRITIS
}

Míriam Küster Huber (HUCAM, Vitoria, ES, Brasil), Maria Bernadete Renoldi de Oliveira Gavi (HUCAM, Vitoria, ES, Brasil), Lucas Marques de Aguiar Ferreira (HUCAM, Vitoria, ES, Brasil), Elisabeth Lima Barboza (HUCAM, Vitoria, ES, Brasil), Leticia Fonseca Favarato (HUCAM, Vitoria, ES, Brasil), Thaís Chaves Belisário (HUCAM, Vitoria, ES, Brasil), Valéria Valim (HUCAM, Vitoria, ES, Brasil), Érica Vieira Serrano (HUCAM, Vitoria, ES, Brasil)

\section{BACKGROUND}

Jaccoud arthropathy (JA) was first described in the 19th century by S. Jaccoud in a patient who had several attacks of rheumatic fever. This arthropathy has also been described in patients with systemic lupus erythematosus with estimated prevalence of $5 \%$, and less frequently in other clinical conditions, like primary hyperparathyroidism and psoriatic arthritis. The classic manifestation of JA is the presence of "reversible deformities," that is reducible to passive movement with preservation of the joint structure. JA generally affects the hands, but can also be observed in feet, knees and shoulders. The most common joint deformities are ulnar deviation, "swan neck," "boutonniere," thumb in Z and hallux valgus. Curiously, in older deformities, a limitation of the joint motion can be observed, probably because of fibrosis secondary contractures of the soft tissues of the joint. The etiopathogenic mechanisms are not known.

\section{CASE REPORT}

A 45 years old male patient is presented in this report who was diagnosed as psoriatic arthritis in 2010. Since then, he has used some different biological treatment with no improvement (Infliximab plus methotrexate since October/2010, switch to Adalimumab since may/2017, switch to Secukinumab since October/2018). He feels diffuse pain, has clinic synovitis in metacarpophalangeal (MCP) and proximal interphalangeal (IP) joints, wrists and shoulders. Ankylosis of the right wrist, deformities as botonière in the fingers and hammer deformities in the toes. Ultrasonography (US) found seven sites with well defined enthesopathy, five ungueal sites with positive PD and moderate active synovitis in 3th and 4th left MCP joints, 1st and 4th left proximal IP joints. Atrophic and scaly atrophic violaceous cutaneous lesions on the knees and legs bilaterally with difficulty of improvement.

\section{CONCLUSION}

Although JA it is most frequently seen in patients with systemic lupus erythematosus, an association with other diseases, like psoriatic arthritis, has occasionally been described. 